\title{
Insulin resistance differentially affects the PI 3-kinase- and MAP kinase-mediated signaling in human muscle
}

\author{
Kenneth Cusi, ${ }^{1}$ Katsumi Maezono, ${ }^{1}$ Abdullah Osman, ${ }^{1}$ Merri Pendergrass, ${ }^{1}$ \\ Mary Elizabeth Patti, ${ }^{2}$ Thongchai Pratipanawatr, ${ }^{1}$ Ralph A. DeFronzo, ${ }^{1}$ \\ C. Ronald Kahn, ${ }^{2}$ and Lawrence J. Mandarino ${ }^{1}$ \\ ${ }^{1}$ Division of Diabetes, Department of Medicine, The University of Texas Health Science Center at San Antonio, \\ San Antonio, Texas 78229, USA \\ ${ }^{2}$ The Joslin Diabetes Center and Harvard Medical School, Boston, Massachusetts 02215, USA
}

Address correspondence to: Lawrence J. Mandarino, Division of Diabetes, Department of Medicine, The University of Texas Health Science Center at San Antonio, 7703 Floyd Curl Drive, San Antonio, Texas 78229-3900, USA.

Phone: (210) 567-6691; Fax: (210) 567-6554; E-mail: mandarino@uthscsa.edu.

Katsumi Maezono’s current address is: Ajinomoto Co. Inc., 214 Maeda-Cho, Totsuka-Ku, Yokohama 244-0804 Japan.

Merri Pendergrass's current address is: Tulane University Medical Center, School of Medicine, Department of Medicine SL53, 1430 Tulane Avenue, New Orleans, Louisiana 70112, USA.

Kenneth Cusi, Katsumi Maezono, and Abdullah Osman contributed equally to this work.

Received for publication June 8, 1999, and accepted in revised form December 15, 1999.

The broad nature of insulin resistant glucose metabolism in skeletal muscle of patients with type 2 diabetes suggests a defect in the proximal part of the insulin signaling network. We sought to identify the pathways compromised in insulin resistance and to test the effect of moderate exercise on wholebody and cellular insulin action. We conducted euglycemic clamps and muscle biopsies on type 2 diabetic patients, obese nondiabetics and lean controls, with and without a single bout of exercise. Insulin stimulation of the phosphatidylinositol 3-kinase (PI 3-kinase) pathway, as measured by phosphorylation of the insulin receptor and IRS-1 and by IRS protein association with $\mathrm{p} 85$ and with PI 3-kinase, was dramatically reduced in obese nondiabetics and virtually absent in type 2 diabetic patients. Insulin stimulation of the MAP kinase pathway was normal in obese and diabetic subjects. Insulin stimulation of glucose-disposal correlated with association of p85 with IRS-1. Exercise 24 hours before the euglycemic clamp increased phosphorylation of insulin receptor and IRS-1 in obese and diabetic subjects but did not increase glucose uptake or PI 3-kinase association with IRS-1 upon insulin stimulation. Thus, insulin resistance differentially affects the PI 3-kinase and MAP kinase signaling pathways, and insulin-stimulated IRS-1-association with PI 3-kinase defines a key step in insulin resistance.

J. Clin. Invest. 105:311-320 (2000).

\section{Introduction}

Insulin resistance characterizes skeletal muscle of patients with type 2 diabetes mellitus and obesity and affects all the metabolic actions of insulin, including glucose transport, hexokinase activity and gene expression, glycogen synthesis, and glucose oxidation (1-5). Because insulin resistance globally affects glucose metabolism, it can be reasoned that a proximal defect, such as in insulin receptor signaling, causes these metabolic abnormalities in muscle. Knowledge of the details of insulin receptor signaling has grown dramatically in recent years. Once insulin binds to its receptor and activates the tyrosine kinase activity of the insulin receptor $\beta$ subunit, insulin signaling pathways diverge. One pathway proceeds through the insulin receptor substrates IRS- 1 and IRS-2 and depends on activation of the enzyme phosphatidylinositol 3-kinase (PI 3 kinase). Another pathway proceeds through Grb2/Sos and ras, leading to activation of the MAP kinase isoforms ERK1 and ERK2. Insulin produces most of its metabolic actions through the PI 3-kinase pathway (6-8). In contrast, inhibition of ERK activation does not reduce insulin-stimulated glucose transport or glycogen synthesis (9).

Details of insulin receptor signaling have been revealed by the use of a variety of in vitro techniques. However, several studies also have examined how insulin resistance alters insulin receptor signaling in vivo in human muscle. Using glucose clamps and muscle biopsies or other techniques, investigators have described abnormalities in insulin-stimulated insulin receptor signaling in muscle from insulin-resistant patients (10-14). In many of these studies, the use of supraphysiological insulin concentrations clouds the interpretation of the results. Moreover, no study to date has reported results concerning the effect of insulin on the MAP kinase pathway in human muscle in vivo, so it is unclear whether insulin resistance also affects the MAP kinase pathway.

Muscle contraction and insulin produce many of the same effects on glucose metabolism. For example, mus- 
cle contraction induces GLUT4 translocation to the cell membrane, activates glycogen synthase, and induces hexokinase II gene expression, independently of insulin (15-19). Chronic exercise training also improves insulin sensitivity (20-23). Despite these close similarities in their effects on glucose metabolism, muscle contraction and insulin use different signaling pathways. Muscle contraction itself does not increase the magnitude of any insulin signaling events in the PI 3-kinase pathway $(16,24-27)$. However, the fact remains that even a single bout of vigorous exercise can enhance insulin action $(28,29)$. It remains unknown, however, whether a single session of moderate exercise can enhance subsequent insulin stimulation of insulin receptor signaling in humans, at a time when the acute effects of exercise on blood flow or other factors has subsided.

The present study was performed to determine first, whether insulin resistance equally affects the PI 3kinase and MAP kinase pathways, and second, how a single bout of moderate exercise alters whole-body and cellular insulin action in type 2 diabetes. The euglycemic clamp technique was combined with muscle biopsies for these purposes. The results show that in obese and type 2 diabetic patients, insulin resistance is present at the level of association of IRS proteins with the regulatory subunit of PI 3-kinase, but does not involve the MAP kinase signaling pathway. A single bout of moderate exercise improves the response of early elements in insulin receptor signaling, but does not affect the abnormality in association of PI 3-kinase with IRS-1 or insulin-stimulated glucose disposal in type 2 diabetes. Therefore, decreased association of PI 3-kinase with IRS-1 is a key defect in insulin resistance in skeletal muscle in type 2 diabetes.

\section{Methods}

Subjects. A total of 27 volunteers (8 lean control subjects, 9 obese nondiabetics, and 10 patients with type 2 diabetes) participated. Their clinical characteristics are shown in Table 1. Normal glucose tolerance was confirmed in obese and control subjects by a 75-g oral glucose tolerance test using American Diabetes Association criteria. The diabetic patients were being treated with diet $(n=2)$ or oral hypoglycemic agents $(n=8)$. Oral agents were discontinued 48 hours before the study. No diabetic subject was receiving insulin. Other than diabetes, none of the subjects had any significant medical problems, and none were taking any medications that are known to affect glucose metabolism. Subjects were instructed to maintain their usual diet for at least 3 days and not to engage in vigorous exercise for at least 2 days before study. The purpose, nature, and potential risks of the

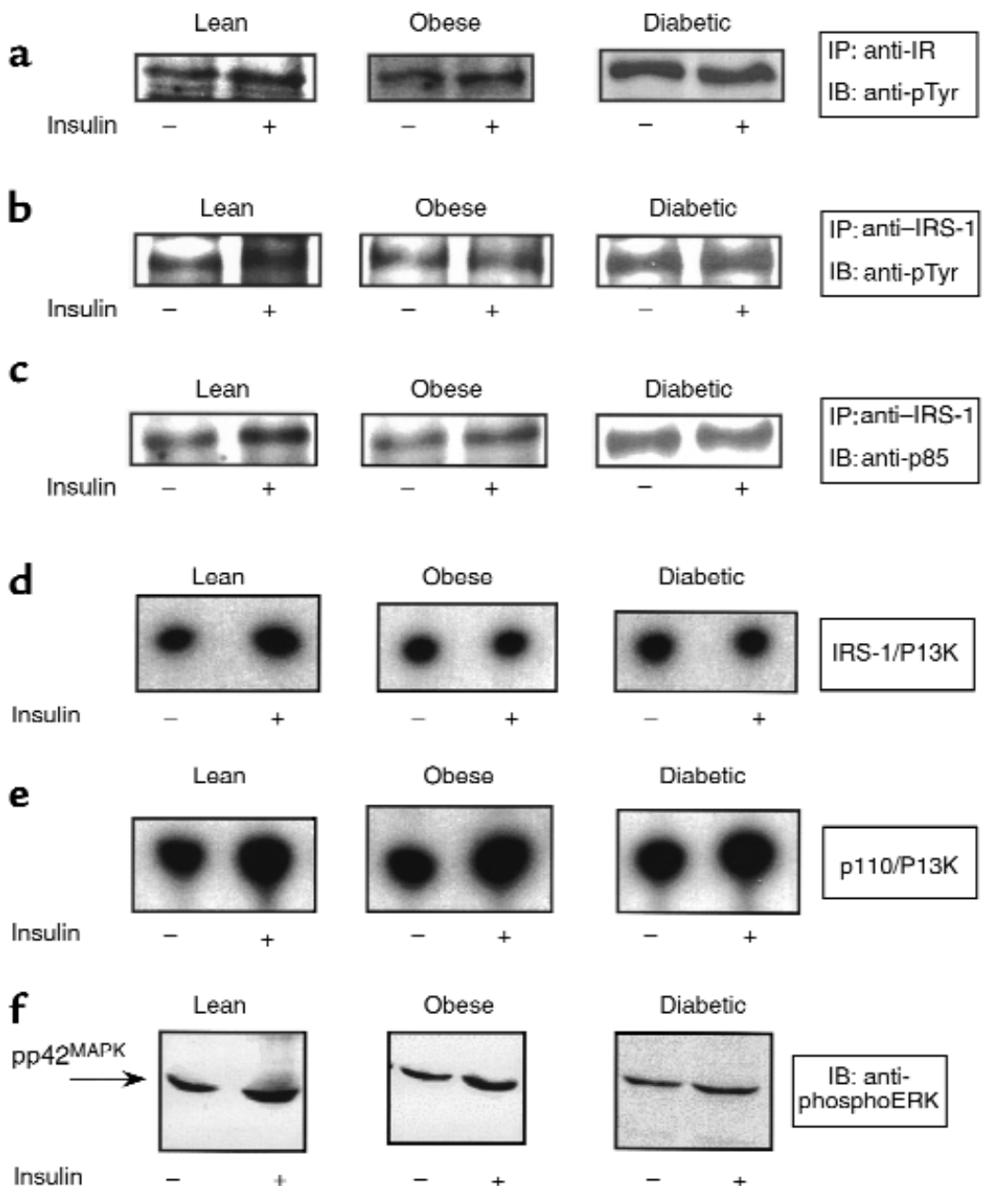

Figure 1

Representative immunoblots. Top panel: Effect of insulin infusion in lean, obese nondiabetic, and type 2 diabetic subjects on insulin receptor (a) and IRS-1 (b) tyrosine phosphorylation, and the association of p85 with IRS-1 (c). Phosphotyrosine content of specific proteins was determined by immunoprecipitation with insulin receptor or IRS-1 antibodies followed by immunoblot analysis with antiphosphotyrosine antibodies. The association of $\mathrm{p} 85$ with IRS- 1 was determined by immunoblot analysis of anti-IRS-1 immunoprecipitates. Bottom panel: Effect of insulin infusion in lean, obese nondiabetic, and type 2 diabetic subjects on PI 3-kinase activity associated with IRS-1 (d) or p110 (e). PI 3-kinase activity was determined as described in the text in anti-IRS-1 immunoprecipitates; effect of insulin infusion on phosphorylation of ERK, determined by immunoblot analysis with an antiphosphoERK antibody (f). pTyr, phosphotyrosine. 
Table 1

Subject characteristics

\begin{tabular}{lccccc}
\hline & Age & Gender & Ethnicity & BMI & Plasma glucose \\
& $(\mathrm{yr})$ & $(\mathrm{M} / \mathrm{F})$ & $(\mathrm{M} / \mathrm{A})$ & $\left(\mathrm{kg} / \mathrm{m}^{2}\right)$ & $(\mathrm{mg} / \mathrm{dL})$ \\
& $34 \pm 5$ & $7 / 1$ & $6 / 2$ & $25.0 \pm 2.0$ & $87 \pm 3$ \\
Lean controls $(n=8)$ & $40 \pm 3$ & $4 / 5$ & $8 / 1$ & $34.2 \pm 1.7^{\mathrm{A}}$ & $92 \pm 2$ \\
Obese nondiabetics $(n=9)$ & $48 \pm 3^{\mathrm{A}}$ & $5 / 5$ & $9 / 1$ & $30.0 \pm 0.9^{\mathrm{A}}$ & $152 \pm 16$ \\
Type 2 diabetics $(n=10)$ & & & & & \\
\hline AP 0.05 versus lean controls. Data are given as means \pm SEM. Ethnicity: M, Mexican \\
American; A, Anglo.
\end{tabular}

where (27). Protein concentration was determined by the Lowry method (31).

Insulin receptor, IRS-1, IRS-2. Two hundred fifty micrograms of soluble protein were used for immunoprecipitation to determine the content of insulin receptor $\beta$ subunit, tyrosine-phosphorylation of proteins, and p85 association with IRS-1. Seven hundred fifty micrograms of protein were used for IRS-2. Immunoprecipitation and immunoblotting were performed as described (27). Protein bands on autoradi-

study were explained to all subjects, and written consent was obtained before their participation. The protocol was approved by the Institutional Review Board of the University of Texas Health Science Center at San Antonio.

Study design. All studies were conducted in the General Clinical Research Center of the University of Texas, Health Science Center at San Antonio and began at 0730 hours after a 10-hour overnight fast. An antecubital vein was cannulated for infusion of insulin and glucose, and a hand vein was cannulated retrogradely and placed in a heated box $\left(60^{\circ} \mathrm{C}\right)$ for sampling of arterialized blood. A primed $(25 \mu \mathrm{Ci})$, continuous infusion of 3 - $\left[{ }^{3} \mathrm{H}\right]$-glucose $(0.25 \mu \mathrm{Ci} / \mathrm{min})$ was started, and 2 hours ( 3 hours for diabetics) was allowed for isotopic equilibration. The priming dose of tritiated glucose was increased in the diabetics in proportion to the increase in their fasting plasma glucose concentration. After a 60 -minute rest, a percutaneous biopsy of the vastus lateralis muscle was obtained (5). Muscle biopsy specimens (75-200 mg) were immediately blotted free of blood, frozen, and stored in liquid nitrogen until use. After 60 minutes, a primed, continuous infusion of insulin was started at a rate of $40 \mathrm{mU} / \mathrm{m}^{2}$ per minute, and plasma glucose was measured with a glucose analyzer (Beckman Instruments, Fullerton, California, USA) at 5 -minute intervals throughout the euglycemic clamp. A variable infusion of $20 \%$ glucose was used to maintain euglycemia. The plasma glucose concentration in the diabetics was allowed to decrease during the insulin infusion to $5 \mathrm{mM}$, at which level it was maintained. Thirty minutes after the start of the insulin infusion, a second muscle biopsy was obtained from a site $4 \mathrm{~cm}$ distal to the first. The insulin infusion was continued for a total of $120 \mathrm{~min}$ utes to obtain an estimate of the rate of glucose disposal (90- to 120-minute period). Glucose-specific activity was determined using barium hydroxide/zinc sulfate extracts of plasma, and glucose disposal rates were calculated using steady-state equations (30). Plasma insulin concentration was determined by radioimmunoassays.

Seven of the 9 obese nondiabetics and all 10 diabetics underwent a second glucose clamp experiment with muscle biopsies 24 hours after 1 hour of cycle ergometer exercise at $65 \%$ of their $\mathrm{VO}_{2} \max$. $\mathrm{VO}_{2}$ max was determined on a separate day using an electrically braked cycle ergometer and a Sensormedics Metabolic Measurement System (Sensormedics, Savi Park, California, USA).

Immunoprecipitation and immunoblotting. Frozen muscle specimens were homogenized as described else- ographs were scanned and quantified with Image Tool software (The University of Texas Health Science Center at San Antonio, Texas, USA). Data were expressed as arbitrary units compared with an aliquot of positive controls. Values for tyrosine phosphorylated molecules were normalized to the content of specific proteins.

ERK phosphorylation. Muscle protein $(250 \mu \mathrm{g})$ was solubilized in SDS sample buffer, boiled for 5 minutes, loaded onto a $10 \%$ SDS-polyacrylamide gel, subjected to electrophoresis, and transferred to nitrocellulose membranes. The membranes were incubated at $4{ }^{\circ} \mathrm{C}$ overnight with rabbit polyclonal phosphospecific ERK1/2 antibody. After washing, the membranes were incubated with secondary antibody (goat-anti-rabbit coupled to horseradish peroxidase) and incubated for 1 hour at room temperature. The membranes were then washed and developed using an enhanced chemiluminescence (ECL) detection system (Amersham Life Sciences, Inc., Arlington Heights, Illinois, USA). The digitized autoradiographs were quantified using Image Tool software. Values were normalized to controls included on each gel.

PI 3-kinase activity. Polyclonal anti-IRS-1 antibody and protein A-Sepharose beads were used for immunoprecipitation of IRS-1-associated PI 3-kinase $(250 \mu \mathrm{g}$ protein). Polyclonal anti-p110- $\alpha$ and anti-p110- $\beta$ antibodies were combined and used for total PI 3-kinase activity determination by immunoprecipitation. Immunoprecipitated PI 3-kinase activity was measured by in vitro phosphorylation of phosphatidylinositol as described elsewhere $(27,32)$. The PI-3 product was identified by its comigration with a PI-4 standard and sensitivity to wortmannin. PI 3-kinase activity was calculated as a value relative to PI 3-kinase activity in a positive control.

ERK2 activity. ERK2 activity was assayed as described elsewhere (33). An aliquot of human muscle protein $(250 \mu \mathrm{g})$ was incubated with $10 \mu \mathrm{L}$ of anti-murine ERK2 polyclonal antibody at $4{ }^{\circ} \mathrm{C}$ overnight and subsequently adsorbed to $80 \mu \mathrm{L}$ of a $50 \%$ slurry of protein Aagarose beads for 2 hours. The immune complexes were washed, and immunoprecipitates were suspended in a reaction buffer containing $20 \mu \mathrm{M}$ ATP, $10 \mu \mathrm{Ci} /$ sample of $\left[\gamma_{-}{ }^{32} \mathrm{P}\right]$ ATP $(6,000 \mathrm{Ci} / \mathrm{mmol})$, and $0.25 \mathrm{mg} / \mathrm{mL}$ myelin basic protein. The suspension was incubated with agitation at $30^{\circ} \mathrm{C}$ for 45 minutes. The reaction was terminated by transferring $25-\mu \mathrm{L}$ aliquots onto P81 phosphocellulose paper discs and washed in $0.75 \%$ 
Table 2

Effect of insulin on whole-body glucose metabolism

\begin{tabular}{|c|c|c|c|c|c|c|}
\hline & & \multirow[t]{2}{*}{ Lean controls } & \multicolumn{2}{|c|}{ Obese nondiabetics } & \multicolumn{2}{|c|}{ Diabetics } \\
\hline & & & No exercise & After exercise & No exercise & After exercise \\
\hline & $n$ & 8 & 9 & 7 & 10 & 10 \\
\hline \multicolumn{7}{|c|}{$\mathrm{HGP}[\mathrm{mg} /(\mathrm{kg} / \mathrm{min})]$} \\
\hline $\begin{array}{l}\text { Basal } \\
\text { Insulin }\end{array}$ & & $\begin{array}{l}2.05 \pm 0.03 \\
0.10 \pm 0.08\end{array}$ & $\begin{array}{c}2.13 \pm 0.19 \\
0.50 \pm 0.12^{\mathrm{A}}\end{array}$ & $\begin{array}{l}1.94 \pm 0.12 \\
0.59 \pm 0.22\end{array}$ & $\begin{array}{l}2.30 \pm 0.24^{\mathrm{A}} \\
0.48 \pm 0.21^{\mathrm{B}}\end{array}$ & $\begin{array}{c}2.04 \pm 0.18^{B} \\
0.47 \pm 0.21\end{array}$ \\
\hline \multicolumn{7}{|c|}{ Glucose disposal [mg/(kg/min $)]$} \\
\hline $\begin{array}{l}\text { Basal } \\
\text { Insulin }\end{array}$ & & $\begin{array}{l}2.05 \pm 0.03 \\
4.36 \pm 0.94\end{array}$ & $\begin{array}{c}2.13 \pm 0.19 \\
3.65 \pm 0.74^{\mathrm{A}}\end{array}$ & $\begin{array}{c}1.94 \pm 0.12 \\
4.32 \pm 0.85^{\mathrm{A}}\end{array}$ & $\begin{array}{l}2.30 \pm 0.24^{\mathrm{A}} \\
2.39 \pm 0.34^{\mathrm{A}}\end{array}$ & $\begin{array}{c}2.04 \pm 0.18^{\mathrm{B}} \\
2.41 \pm 0.45^{\mathrm{A}}\end{array}$ \\
\hline
\end{tabular}

AP 0.05 versus lean controls. ${ }^{B} P<0.05$ versus "no exercise" value. Data are expressed in units of $\mathrm{mg} /(\mathrm{kg} / \mathrm{min})$ and are given as means $\pm \mathrm{SEM}$. Post-exercise statistical comparisons on the obese nondiabetics were performed using the 7 subjects who completed both studies.

$\mathrm{H}_{3} \mathrm{PO}_{4}$. The discs were washed once with acetone and air-dried, and the ${ }^{32} \mathrm{P}$ incorporated into myelin basic protein was measured by liquid scintillation counting. Specific kinase activity was determined by subtracting the radioactivity in the absence of substrate from that in the presence of substrate. Western blotting was performed on a portion of the immunoprecipitates, and the radioactivity was normalized for ERK- 2 content.

MEK1 activity. MEK1 activity was assayed as described previously (34). Muscle protein $(250 \mu \mathrm{g})$ was incubated with $1.25 \mu \mathrm{g} /$ tube of anti-MEK $1 \mathrm{mAb}$ at $4^{\circ} \mathrm{C}$ for 3 hours followed by incubation with $50 \mu \mathrm{L}$ of protein $\mathrm{G}$ agarose beads for an additional 2 hours. Immunoprecipitates were washed, and the immune complexes were resuspended in MEK1 kinase buffer containing $50 \mu \mathrm{M}$ ATP, $10 \mu \mathrm{Ci} / \mathrm{sample}$ of $\left[\gamma^{-32} \mathrm{P}\right]$ ATP $(6,000 \mathrm{cpm} / \mathrm{pmol})$, and a recombinant kinase-inactive mouse GST-MAPK $(1.4 \mu \mathrm{g} /$ tube, $)$ as substrate. The suspension was incubated with agitation for 30 minutes at $30^{\circ} \mathrm{C}$, and the reaction was stopped by adding $40 \mu \mathrm{L}$ of SDS sample buffer. Products were boiled for 5 minutes and resolved on $10 \%$ SDS-PAGE. The gel was dried, and phosphorylated GST-ERK2 bands ( $62 \mathrm{kDa}$ ) were quantified using a PhosphorImager and ImageQuant Software (Molecular Dynamics, Inc., California, USA).

Glycogen synthase activity. Glycogen synthase (GS) activity was assayed as described (5). Activity was determined in the presence of $0.1\left(\mathrm{GS}_{0.1}\right)$ and $10\left(\mathrm{GS}_{10}\right) \mathrm{mM}$ glucose 6-phosphate (G6P). GS fractional velocity $\left(\mathrm{GS}_{\mathrm{Fv}}\right)$ is the ratio $\mathrm{GS}_{0.1} / \mathrm{GS}_{10}$.

Materials. Polyclonal anti-insulin receptor $\beta$ subunit, anti-IRS-1, anti-p85, anti-p110-alpha, anti-p110- $\beta$, anti-ERK2, and monoclonal antiphosphotyrosine (4G10) antibodies, and GST-MAP kinase were purchased from Upstate Biotechnology (Lake Placid, New York, USA). The polyclonal anti-IRS-2 (JD250) antibody was used as described previously (35). Radioisotopes were purchased from DuPont/NEN (Wilmington, Delaware, USA). PI was from Avanti Polar Lipids (Alabaster, Alabama, USA). Regular human recombinant insulin was obtained from Eli Lilly \& Co. (Indianapolis, Indiana, USA). Phosphocellulose paper (p81) and Silica gel 60 TLC plates were purchased from Whatman, Inc.
(Clifton, New Jersey, USA). Reagents for SDS-PAGE were from Bio-Rad Laboratories Inc. (Richmond, California, USA). The ECL detection system and secondary antibodies were purchased from Amersham Life Science (Arlington Heights, Illinois, USA). Anti-MEK1 antibody was from Transduction Laboratories (Lexington, Kentucky, USA). All other reagents were purchased from Sigma Chemical Co. (St. Louis, Missouri, USA).

Statistical methods. The data are presented as means \pm SE. The ability of insulin treatment to increase insulin signaling events, glycogen synthase activity, or glucose disposal was compared with basal values using 1-tailed paired $t$ tests. Multiple comparisons among groups and timecourse studies were tested by ANOVA, using StatView software (version 4.0; SAS Inc., Cary, North Carolina, USA). Correlation analysis was performed by the Pearson product moment method. Stepwise multiple regression analysis was done using Minitab Statistical Software (Minitab, Inc., State College, Pennsylvania, USA).

\section{Results}

Metabolic characteristics and insulin stimulation of glucose disposal. Metabolic data and PI 3-kinase signaling data from 5 of the 8 control subjects has been reported (27). Euglycemic clamp experiments were performed to assess the effects of insulin on glucose metabolism (Tables 1 and 2). Plasma insulin concentrations were $7 \pm 1,13 \pm 1$, and 18 $\pm 1 \mu \mathrm{U} / \mathrm{mL}$ basally and $69 \pm 5,96 \pm 5$, and $92 \pm 7 \mu \mathrm{U} / \mathrm{mL}$ during the euglycemic clamp in lean, obese, and diabetic subjects. Insulin increased glucose disposal in lean control and obese nondiabetic subjects $(P<0.05)$, but had no effect in the diabetics. Basal hepatic glucose production (HGP) was increased in the diabetics $(P<0.05)$. Insulin suppressed HGP completely in the lean control subjects, but only by about $75 \%$ in the obese nondiabetics and diabetics. The ability of a bout of moderate exercise (65\% of $\mathrm{VO}_{2}$ max) to influence subsequent insulin stimulation of insulin receptor signaling 24 hours later was studied in 7 of 9 obese nondiabetic controls and all 10 type 2 diabetics. The obese nondiabetics and type 2 diabetics who participated in the exercise studies had a $\mathrm{VO}_{2} \max$ of $24.1 \pm$ $2.7 \mathrm{~mL} / \mathrm{kg}$ per minute $(2.16 \pm 0.30 \mathrm{~L} / \mathrm{min})$ and $21.9 \pm 1.5$ $\mathrm{mL} / \mathrm{kg}$ per minute $(1.79 \pm 0.13 \mathrm{~L} / \mathrm{min})$, respectively $(P=$ 
NS). Exercise significantly $(P<0.05)$ decreased basal HGP in the type 2 diabetics; fasting plasma glucose concentrations were $152 \pm 16$ and $144 \pm 15 \mathrm{mg} / \mathrm{dL}$, respectively $(P$ $=$ NS). Exercise improved insulin-stimulated glucose disposal in the obese nondiabetics, but had no effect on glucose disposal in the diabetics.

Glycogen synthase activity. Insulin infusion significantly increased $\mathrm{GS}_{0.1}$, but not $\mathrm{GS}_{10}$, activity in lean control subjects to a value $152 \pm 13 \%$ of basal values (Table 3 ). Insulin infusion also increased $\mathrm{GS}_{0.1}$ activity in obese nondiabetics to a lesser degree than in lean controls. This difference was not statistically significant. Basal $\mathrm{GS}_{0.1}$ activity and insulin stimulation of glycogen synthase activity were reduced significantly in the diabetics. Exercise increased $\mathrm{GS}_{0.1}$ basally and after insulin infusion in the obese controls and diabetics.

Time course of insulin stimulation of insulin receptor and IRS-1 tyrosine phosphorylation. In 2 subjects, muscle biopsies were performed before and after 15 and 30 minutes of infusion of insulin at a rate of $40 \mathrm{mU} /\left(\mathrm{m}^{2} / \mathrm{min}\right)$. Insulin stimulated both insulin receptor and IRS-1 tyrosine phosphorylation by 15 minutes, and this level of phosphorylation was sustained for at least 30 minutes.

Insulin receptor and IRS-1 tyrosine phosphorylation: effect of obesity, diabetes, and exercise. The ability of insulin to increase tyrosine phosphorylation of the insulin receptor was assayed by immunoprecipitation of insulin receptors followed by immunoblot analysis with an antiphosphotyrosine antibody. Data are given in Table 4, and representative immunoblots are shown in Figure 1. The modest (about 50\%), but significant $(P<0.05)$, increase in phosphotyrosine content of the receptor $\beta$ subunit in lean control subjects after insulin stimulation reflects the physiological nature of the insulin stimulation. In contrast, hyperinsulinemia did not increase tyrosine phosphorylation of the insulin receptor $\beta$ subunit in either obese nondiabetic or type 2 diabetic patients. Tyrosine phosphorylation of IRS-1 was increased after insulin stimulation by 2 -fold in lean control subjects $(P<0.05)$, but there was no effect in the diabetics (Table 4). In contrast to the results with the insulin receptor, insulin increased IRS-1 tyrosine phosphorylation significantly in obese nondiabetics $(P<$ $0.05)$. Prior exercise significantly increased insulin-stimulated insulin receptor tyrosine phosphorylation in both groups (161 \pm 18 and $134 \pm 21 \%$ of basal values for obese and diabetic subjects; $P<0.05$ for both). Neither group was restored fully to normal values, however (Figure 2). Exercise significantly reduced basal insulin receptor tyrosine phosphorylation, compared with pre-exercise values, in the diabetics (Figure 2; $P<0.05$ ). Exercise also significantly improved the response of IRS-1 tyrosine phosphorylation to insulin in the diabetic group $(P<0.05)$, but this was still significantly less than that of lean control subjects who were studied without exercise $(P<0.05)$. Similar to insulin receptor phosphorylation, this was due primarily to decreased basal tyrosine phosphorylation. Insulin did not affect insulin receptor or IRS-1 protein. Insulin receptor protein was $2.42 \pm 0.32,2.70 \pm 0.30$, and $2.82 \pm 0.26$ arbitrary units, and IRS- 1 protein was $0.97 \pm 0.07,0.95 \pm$
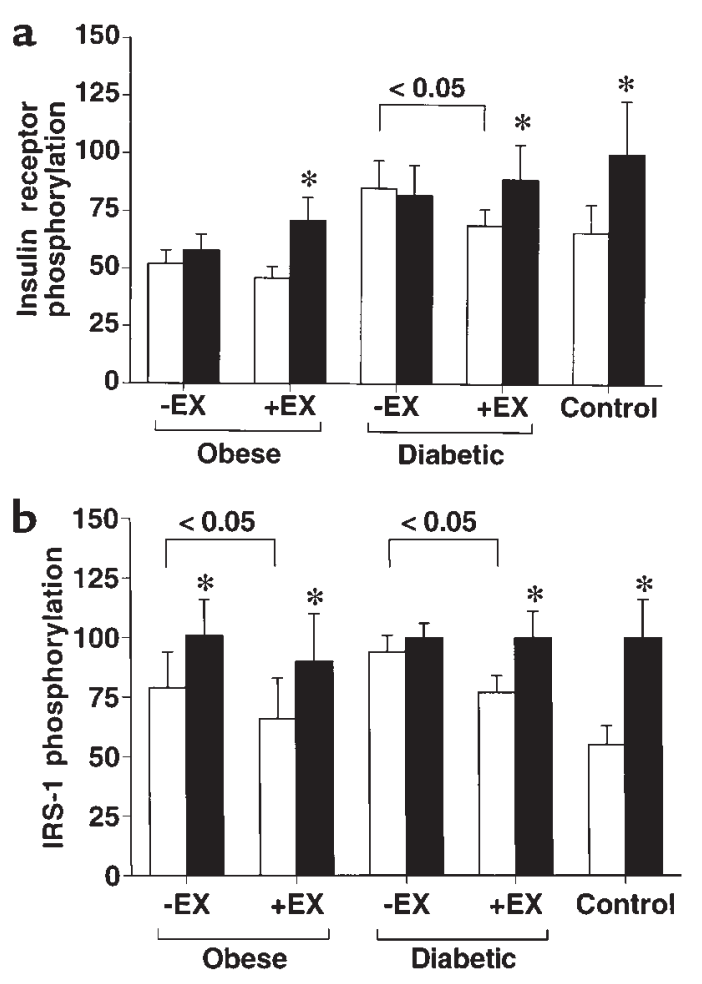

Figure 2

Effect of exercise on subsequent insulin stimulation of insulin receptor (a) and IRS-1 (b) tyrosine phosphorylation. Obese $(n=7)$ and diabetic $(n=10)$ subjects underwent euglycemic clamps with muscle biopsies twice: 1 time without prior exercise and again 24 hours after a single 1-hour bout of moderate exercise. Homogenates of muscle biopsy specimens were immunoprecipitated with antibodies directed against the insulin receptor $\beta$ subunit or IRS-1. Immunoprecipitated proteins were resolved on polyacrylamide gels, transferred to nitrocellulose membranes, probed with an antiphosphotyrosine antibody, and detected by chemiluminescence, and the digitized images were quantified. Basal values are shown as open bars, and insulinstimulated values are shown as filled bars. Data were normalized to insulin receptor $\beta$ subunit or IRS-1 protein content (determined on separate immunoblots) and are expressed as percent of the mean insulin-stimulated value in the lean control subjects. Data are presented as means \pm SEM. ${ }^{*} P<0.05$ versus basal values.

0.12 , and $1.04 \pm 0.07$ arbitrary units in lean, obese, and diabetic subjects, respectively.

Association of $p 85$ and PI 3-kinase activity with IRS-1. The association of the p85 regulatory subunit of PI 3-kinase with IRS-1 was determined by quantifying $\mathrm{p} 85$ protein in IRS-1 immunoprecipitates (Figure 1 and Table 4). Insulin stimulated the association of p 85 with IRS- 1 by $62 \pm 12 \%$, and this was similar in lean control and obese nondiabetics. Insulin did not increase the association of $\mathrm{p} 85$ with IRS- 1 in the diabetics. The pattern of insulin stimulation of PI 3-kinase activity associated with IRS-1 paralleled p85 binding to IRS-1. Insulin stimulated the association of PI 3-kinase activity with IRS-1 in lean control $(2.13 \pm 0.42$ fold; $P<0.01)$ and obese nondiabetic $(1.68 \pm 0.20$ fold; $P<$ $0.05)$ subjects but did not significantly increase the association of PI 3-kinase activity with IRS-1 in muscle from the type 2 diabetic patients. The activity of PI 3-kinase was 


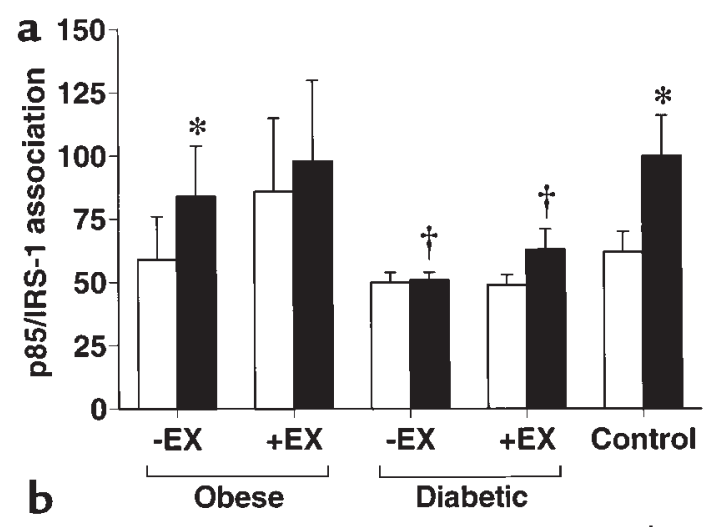

immunoprecipitates using immunoblot analysis in 5 lean control subjects and in 6 each of the obese and diabetic subjects. In lean controls, insulin increased the association of $\mathrm{p} 85$ with IRS-2 from a basal value of $0.124 \pm 0.031$ to $0.178 \pm 0.029(P<0.05)$. In obese nondiabetics, insulin infusion increased the association of p85 with IRS-2 from $0.171 \pm 0.036$ to $0.243 \pm 0.046$ ( $P$ $<0.05)$. Insulin infusion did not increase the association of p85 with IRS- 2 in diabetics $(0.203 \pm 0.040$ basally versus $0.206 \pm 0.032$ after insulin).

MAP kinase pathway activity. MAP kinase pathway activity was assessed in 3 ways. Phosphorylation of ERK1 and ERK2 was assayed using immunoblot analysis with an antibody directed against the doubly phosphorylated ERKs. ERK activity was determined by the ability of ERK2 immunoprecipitates to phosphorylate myelin basic protein, and MEK1 activity was assayed by the ability of MEK1 immunoprecipitates to phosphorylate an inactive recombinant GST-ERK protein. The results are given in Table 5, and representative immunoblots are shown in Figure 1. In contrast to the defective insulin receptor signaling pathway through IRS-1 and PI 3kinase, insulin increased ERK phosphorylation, ERK activity, and MEK1 activity in insulin-resistant patients to the same extent as lean controls. There were no significant differences for ERK and MEK activities or ERK phosphorylation among the 3 groups. The effect of exercise on insulin stimulation of the MAP kinase pathway was different than that for the other signaling events. The responses of ERK phosphorylation, ERK activity, and MEK1 activity to insulin all were increased by exercise to values that exceeded the insulin-stimulated, but nonexercised, values in lean controls (Figure 4). Insulin had no effect on ERK2 protein content, which was 1.58 $\pm 0.11,1.51 \pm 0.27$, and $1.58 \pm 0.25$ arbitrary units in lean, obese, and diabetic subjects, respectively.

In vitro insulin receptortyrosine kinase activity and Shc phosphorylation. The MAP kinase pathway was activated by insulin in the diabetics despite the lack of a detectable insulin-stimulated increase in insulin receptor phosphorylation. To determine the potential tyrosine kinase activity of the insulin receptor, muscle homogenates in a subgroup of the control and diabetic subjects were exposed to insulin $(100 \mathrm{ng} / \mathrm{mL})$ in the presence of [32P]ATP. Insulin receptors were immunoprecipitated and resolved by SDS-PAGE, and ${ }^{32} \mathrm{P}$ content was quantified by PhosphorImage analysis. In lean controls $(n=6)$, insulin increased the incorporation of ${ }^{32} \mathrm{P}$ into insulin receptor protein from $1.39 \pm 0.45$ to $2.33 \pm 0.95$ arbitrary units $(P<0.05)$. In diabetics $(n=6)$, insulin increased incorporation of ${ }^{32} \mathrm{P}$ into insulin receptor protein from $1.26 \pm 0.48$ to $2.12 \pm 0.50$ arbitrary units $(P<0.05)$. To determine whether Shc is phosphorylated residues by insulin, muscle biopsy homogenates were immunoprecipitated with an anti-Shc antibody followed by immunoblot analysis with an antiphosphotyrosine antibody. Insulin increased Shc tyrosine phosphorylation from $9.05 \pm 0.34$ to $14.9 \pm 0.61$, from $10.1 \pm 0.35$ to 15.1 \pm 0.40 , and from $9.72 \pm 0.47$ to $15.8 \pm 0.33$ in lean con- 
Table 3

Glycogen synthase activities

\begin{tabular}{|c|c|c|c|c|c|c|c|c|}
\hline \multirow[b]{3}{*}{$\mathrm{G} 6 \mathrm{P}(\mathrm{mM})$} & \multicolumn{4}{|c|}{ No exercise } & \multicolumn{4}{|c|}{ After exercise } \\
\hline & \multicolumn{2}{|c|}{ Basal } & \multicolumn{2}{|c|}{ Insulin } & \multicolumn{2}{|c|}{ Basal } & \multicolumn{2}{|c|}{ Insulin } \\
\hline & 0.1 & 10 & 0.1 & 10 & 0.1 & 10 & 0.1 & 10 \\
\hline $\begin{array}{l}\text { Lean } \\
\text { controls }(n=8)\end{array}$ & $0.373 \pm 0.057$ & $2.71 \pm 0.39$ & $0.572 \pm 0.112^{\mathrm{A}}$ & $2.92 \pm 0.42$ & - & - & - & - \\
\hline $\begin{array}{l}\text { Obese } \\
\text { nondiabetics }(n=9)\end{array}$ & $0.382 \pm 0.046$ & $2.01 \pm 0.22^{B}$ & $0.499 \pm 0.054^{\mathrm{A}}$ & $2.21 \pm 0.15$ & $0.534 \pm 0.085^{c}$ & $1.96 \pm 0.12^{\mathrm{B}}$ & $0.655 \pm 0.089^{A, C}$ & $2.04 \pm 0.07^{\mathrm{B}}$ \\
\hline $\begin{array}{l}\text { Type } 2 \\
\text { diabetics }(n=10)\end{array}$ & $0.273 \pm 0.03^{\mathrm{B}}$ & $1.99 \pm 0.22^{\mathrm{B}}$ & $0.354 \pm 0.032^{\mathrm{A}}$ & $1.91 \pm 0.16^{\mathrm{B}}$ & $0.342 \pm 0.028$ & $1.62 \pm 0.14^{B}$ & $0.523 \pm 0.055^{A, C}$ & $1.93 \pm 0.22^{\mathrm{B}}$ \\
\hline
\end{tabular}

trols, obese nondiabetics, and diabetics, respectively (all arbitrary units, all $P<0.05$, insulin versus basal).

Correlations. The associations between insulin stimulation of insulin signaling elements and glucose disposal were assessed by correlation analysis. Insulin-stimulated glucose disposal was positively correlated with the insulinstimulated increment in glycogen synthase activity $(r=$ $0.457 ; P<0.05)$, IRS- 1 tyrosine phosphorylation $(r=0.436$; $P<0.05)$, and association of $\mathrm{p} 85$ with IRS- $1(r=0.424 ; P<$ $0.05)$. Multiple linear regression revealed that insulinstimulated glucose disposal was independently correlated with glycogen synthase activity and association of $\mathrm{p} 85$ with IRS-1 $\left(r^{2}=0.43 ; P<0.005\right)$. Insulin stimulation of IRS-1 tyrosine phosphorylation was correlated with association of p85 with IRS- $1(r=0.806 ; P<0.001)$ and with association of PI 3-kinase activity with IRS-1 $(r=0.582 ; P$ $<0.01)$. Activation of the MAP kinase pathway was not correlated with insulin stimulation of glucose disposal.

\section{Discussion}

Previous studies have shown that obese and type 2 diabetic patients have reduced insulin receptor tyrosine kinase activity and reduced intracellular signaling compared with lean control subjects $(10-14,26)$. However, these studies have not dissected the impact of insulin resistance on the divergent pathways of insulin action. The present study was undertaken, in part, to determine whether insulin resistance affects both the PI 3-kinase and MAP kinase pathways of insulin receptor signaling similarly, as these appear to be linked to different downstream effects; that is, PI 3-kinase is coupled to most metabolic actions, whereas MAP kinase may be linked to cell growth and gene expression (6-9). Physiological hyperinsulinemia increased tyrosine phosphorylation of the insulin receptor and IRS- 1 in lean controls to $150-200 \%$ of basal values. Obese nondiabetics had reduced insulin stimulation of these 2 early insulin receptor signaling events, and insulin had no significant effect on either insulin receptor or IRS-1 tyrosine phosphorylation in the type 2 diabetic patients. Furthermore, insulin activation of the association of $\mathrm{p} 85$ protein or PI 3-kinase activity was greatly reduced in obese and type 2 diabetic subjects compared with lean controls.

The lack of increase in tyrosine phosphorylation of the $\beta$ subunit of the insulin receptor in the diabetics seems to represent a more profound abnormality than the moderate decrease in insulin receptor tyrosine kinase activity reported in other studies (10). This may reflect the more physiological nature of the insulin stimulation in the present study or may be indirect evidence of increased activity of protein tyrosine phosphatases $(36,37)$. To test whether insulin was able to stimulate the tyrosine kinase of the receptor $\beta$ subunit, receptors were exposed to insulin and then immunoprecipitated while phosphatase activity was inhibited. Insulin increased receptor tyrosine kinase activity to

Table 4

Insulin receptor signaling through the PI 3-kinase pathway

\begin{tabular}{|c|c|c|c|c|c|c|}
\hline & \multicolumn{2}{|c|}{ Lean controls $(n=8)$} & \multicolumn{2}{|c|}{ Obese nondiabetics $(n=9)$} & \multicolumn{2}{|c|}{ Type 2 diabetics $(n=10)$} \\
\hline & Basal & Insulin & Basal & Insulin & Basal & Insulin \\
\hline Insulin receptor phosphorylation & $0.415 \pm 0.077$ & $0.624 \pm 0.141^{\mathrm{A}}$ & $0.433 \pm 0.0132$ & $0.416 \pm 0.082^{B}$ & $0.529 \pm 0.075$ & $0.514 \pm 0.078^{\mathrm{B}}$ \\
\hline IRS-1 phosphorylation & $0.485 \pm 0.073$ & $0.875 \pm 0.140^{\mathrm{A}}$ & $0.691 \pm 0.121$ & $1.015 \pm 0.150$ & $0.819 \pm 0.058^{B}$ & $0.879 \pm 0.055$ \\
\hline p85 association with IRS-1 & $0.384 \pm 0.053$ & $0.623 \pm 0.101^{\mathrm{A}}$ & $0.383 \pm 0.093$ & $0.665 \pm 0.148^{A}$ & $0.312 \pm 0.025$ & $0.315 \pm 0.016^{\mathrm{B}, \mathrm{C}}$ \\
\hline IRS-1-associated PI 3-kinase activity & $0.105 \pm 0.017$ & $0.218 \pm 0.045^{\mathrm{A}}$ & $0.096 \pm 0.015$ & $0.151 \pm 0.02^{\mathrm{A}}$ & $0.094 \pm 0.017$ & $0.121 \pm 0.022^{\mathrm{B}}$ \\
\hline $\begin{array}{l}\text { Total (p110-associated) } \\
\text { PI 3-kinase activity }\end{array}$ & $0.845 \pm 0.351$ & $1.83 \pm 0.60^{\mathrm{A}}$ & $0.591 \pm 0.194$ & $0.802 \pm 0.177^{B}$ & $0.385 \pm 0.135$ & $0.539 \pm 0.206^{\mathrm{B}}$ \\
\hline
\end{tabular}



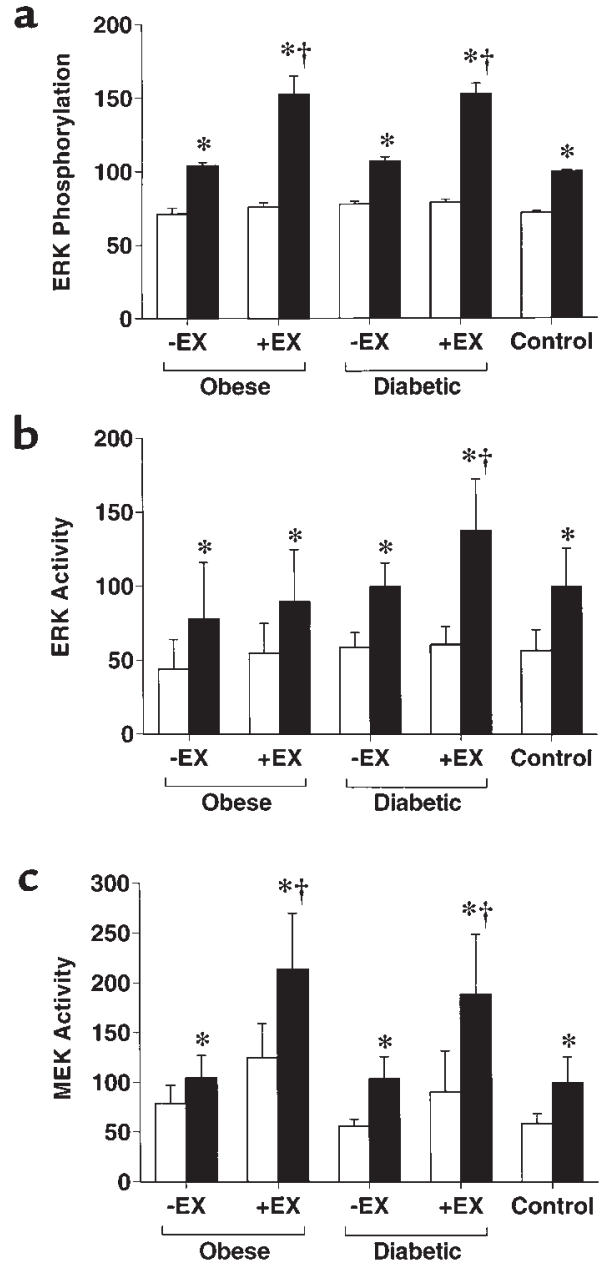

\section{Figure 4}

Effect of exercise on insulin stimulation of ERK phosphorylation (a), ERK activity (b), and MEK activity $(\mathbf{c})$. Obese $(n=6)$ and diabetic $(n=6)$ subjects underwent euglycemic clamps with muscle biopsies twice: 1 time without prior exercise and again 24 hours after a single 1-hour bout of moderate exercise. Homogenates of muscle biopsy specimens were analyzed for ERK phosphorylation by immunoblot analysis using an antiphosphoERK antibody. ERK activity was determined as described in the text using anti-ERK immunoprecipitates, and MEK activity was assayed using anti-MEK immunoprecipitates. Basal values are shown as open bars, and insulin-stimulated values are shown as filled bars. Data are presented as means \pm SEM. ${ }^{*} P<$ 0.05 versus basal values. ${ }^{\dagger} P<0.05$ versus lean control values.

the same extent in diabetics and in lean control subjects. This indicates that the insulin receptor in the diabetics retains, at least in vitro, responsiveness to insulin. The fact that obese nondiabetic subjects have some detectable insulin stimulation of IRS- 1 tyrosine phosphorylation even though insulin receptor phosphorylation was not significantly increased supports the concept that receptor tyrosine kinase activity is not reduced to as great an extent as insulin receptor tyrosine phosphorylation. Regardless, the present data indicate that there is profound resistance to insulin's ability to activate the PI 3-kinase signaling pathway in obese and especially type 2 diabetic patients.
Recent studies suggest that an abnormality in IRS-1 function is not sufficient to produce insulin resistance that can lead to diabetes (38) but that an IRS-2 knockout mouse becomes hyperglycemic. In contrast, another study suggests that IRS-2 acts as a compensatory signaling protein for IRS- 1 in adipocytes isolated from type 2 diabetics (39), in a similar way that it compensates for the loss of IRS- 1 in the IRS-1 knockout mouse (35). To address this issue in human muscle, IRS-2 protein and insulin stimulation of the association of $\mathrm{p} 85$ protein with IRS-2 were assayed. The results show that although IRS2 expression was found to be normal in the diabetics, insulin did not stimulate the association of p 85 with IRS2 . This defect is similar to the IRS- 1 abnormality observed here, and suggests that type 2 diabetes is characterized by a combined defect in IRS- 1 and IRS- 2 function.

The profound insulin resistance of the PI 3-kinase signaling pathway contrasts markedly with the ability of insulin to stimulate MAP kinase pathway activity in insulin-resistant individuals. Hyperinsulinemia increased MEK1 activity and ERK1/2 phosphorylation and activity to the same extent in lean controls as in insulin-resistant obese nondiabetic and type 2 diabetic patients. That is, insulin resistance does not affect the MAP kinase signaling pathway in vivo in humans. This finding of selective insulin resistance is similar to that recently observed in vasculature of Zucker fatty rats (40). Two possible reasons for this difference are alternate insulin signaling pathways and differential signal amplification. With regard to the former, the MAP kinase pathway can be activated either through Grb2/Sos interaction with IRS-1/2 or with Shc. Because IRS-1 tyrosine phosphorylation is dramatically reduced in the diabetics, it is possible that insulin activation of the MAP kinase pathway in vivo primarily occurs through Shc activation. Evidence from in vitro studies supports this concept (41). Like ERK and MEK activity, insulin stimulated Shc phosphorylation to the same extent in lean, obese, and type 2 diabetic subjects. We propose that in diabetes, insulin induces sufficient activation of the insulin receptor tyrosine kinase to increase Shc phosphorylation normally. It is also possible that differential signal amplification in the PI 3-kinase and MAP kinase pathways can explain their differing susceptibilities to the effects of insulin resistance.

Maintenance of insulin stimulation of the MAP kinase pathway in the presence of insulin resistance in the PI 3-kinase pathway may be important in the development or maintenance of insulin resistance. ERKs can phosphorylate IRS-1 on serine residues (42), and serine phosphorylation of IRS-1 and the insulin receptor itself has been implicated in desensitizing insulin receptor signaling (43). Continued ERK activity when IRS-1 function is already impaired could lead to a worsening of insulin resistance. Thus, the diabetic and obese subjects may have inappropriately high MAP kinase activity.

Another purpose of the present study was to gain evidence regarding which steps in insulin signaling have the greatest impact on insulin action. First, insulin stim- 
Table 5

Insulin receptor signaling through the MAP kinase pathway

\begin{tabular}{|c|c|c|c|c|c|c|}
\hline \multirow{3}{*}{$n$} & \multicolumn{2}{|c|}{ Lean controls } & \multicolumn{2}{|c|}{ Obese nondiabetics } & \multicolumn{2}{|c|}{ Type 2 diabetics } \\
\hline & \multicolumn{2}{|c|}{8} & \multicolumn{2}{|c|}{9} & \multicolumn{2}{|c|}{10} \\
\hline & Basal & Insulin & Basal & Insulin & Basal & Insulin \\
\hline ERK phosphorylation & $0.659 \pm 0.013$ & $0.918 \pm 0.009^{A}$ & $0.652 \pm 0.021$ & $0.936 \pm 0.021^{\mathrm{A}}$ & $0.720 \pm 0.018$ & $0.980 \pm 0.025^{A}$ \\
\hline ERK activity & $1.384 \pm 0.327$ & $2.420 \pm 0.623^{\mathrm{A}}$ & $1.110 \pm 0.316$ & $1.832 \pm 0.527^{\mathrm{A}}$ & $1.425 \pm 0.191$ & $2.408 \pm 0.319^{A}$ \\
\hline MEK1 activity & $0.716 \pm 0.124$ & $1.213 \pm 0.312^{\mathrm{A}}$ & $0.801 \pm 0.142$ & $1.294 \pm 0.172^{\mathrm{A}}$ & $0.685 \pm 0.065$ & $1.268 \pm 0.213^{A}$ \\
\hline
\end{tabular}

AP $<0.05$ versus basal values. Data are given as means \pm SEM. ERK phosphorylation was determined by scanning densitometry after immunoblot analysis, and data are expressed in arbitrary density units. ERK and MEK1 activity are expressed as disintegrations per minute relative to ERK or MEK1 protein content determined by scanning densitometry following immunoblot analysis.

ulation of glycogen synthase activity was positively correlated with systemic glucose disposal. This has been interpreted to indicate that glucose stored as glycogen in skeletal muscle is a predominant pathway of insulinstimulated glucose disposal $(1,5)$. Second, insulin stimulation of the association of the p85 regulatory subunit of PI 3-kinase with IRS-1 also was significantly correlated with insulin-stimulated glucose disposal, independent of the correlation of glycogen synthase activity with glucose disposal. Although insulin stimulation of IRS-1 tyrosine phosphorylation was correlated with both p85 and PI 3-kinase activity associated with IRS-1, only p85 association with IRS- 1 was independently correlated with glucose disposal. These analyses provide evidence that decreased association of p85 with IRS-1 could be a key abnormality related to skeletal muscle insulin resistance.

This study was also undertaken to assess the effect of a single session of moderate intensity exercise on insulin action in the whole body and on a cellular level. Vigorous exercise increases insulin sensitivity (29). However, in the present study, moderate exercise (about $65 \%$ of $\mathrm{VO}_{2} \max$ ) was used because such exercise is more realistic in everyday life for the average diabetic patient. Patients were studied 24 hours after the exercise bout to remove any confounding acute effects of exercise such as increased muscle blood flow or other systemic effects. Despite the moderate nature of this exercise, there were significant effects on muscle. Glycogen synthase activity and MAP kinase pathway activity were increased, and insulin receptor and IRS-1 tyrosine phosphorylation in response to insulin were improved. Moreover, basal HGP was normalized in the diabetic patients. Therefore even 1 mild exercise session can have beneficial effects in type 2 diabetics. Despite this, in diabetic patients, exercise did not improve the ability of insulin to increase either the rate of glucose disposal or the association of PI 3-kinase with IRS-1. Given that the association of PI 3-kinase with IRS- 1 is a key rate-limiting step in insulin action, it is not surprising that exercise also did not improve insulin's ability to stimulate glucose uptake. Exercise increases the activity of glycogen synthase as well as its sensitivity to activation by insulin $(10,44)$. This was clearly the case in the present study, as exercise increased basal and insulinstimulated glycogen synthase activity to nearly normal levels in the type 2 diabetics. The fact that exercise did not increase insulin-stimulated glucose uptake provides clear evidence that normal insulin activation of skeletal muscle glycogen synthase is insufficient to increase insulin-stimulated glucose uptake. Therefore, even though it is possible to increase glucose uptake by overexpressing glycogen synthase in transgenic mice (45), it seems that an increase in glycogen synthase activity alone is insufficient to increase glucose disposal in humans. This is consistent with studies using nuclear magnetic resonance spectroscopy (46) or mathematical modeling of glucose tracer kinetics (3) that have found either glucose transport or glucose phosphorylation to determine the rate of glucose uptake in humans.

Other studies, using more intense exercise in healthy human volunteers (47) or rodents (25), or a single bout of moderate exercise in healthy humans (27), also failed to find an effect of exercise on insulin receptor signaling. The present results with respect to PI 3-kinase activity are consistent with these studies, although the finding of increased insulin receptor and IRS-1 tyrosine phosphorylation in response to insulin differs from those earlier results. One major difference that could explain this is that profoundly insulin-resistant subjects were used in the current study, whereas earlier investigations used healthy subjects (47). Regardless, the increases in insulin receptor and IRS-1 tyrosine phosphorylation that were observed here were not sufficient to increase insulin-stimulated glucose uptake. In contrast to the lack of effect of exercise on insulin signaling through the PI 3-kinase pathway, exercise increased the ability of insulin to stimulate ERK1/2 and MEK1 activity in the insulin-resistant patients. Because the role of the MAP kinase pathway in the various effects of insulin remains obscure, the significance of this effect of exercise is not clear. It is possible that the exercise-induced increase in MAP kinase activity is associated with a training response of skeletal muscle.

In summary, the present study shows that in insulinresistant subjects with obesity or type 2 diabetes, there is profound insulin resistance in the PI 3-kinase pathway of insulin receptor signaling, whereas the MAP kinase pathway is normal. Moreover, in type 2 diabetes, a single bout of moderate-intensity exercise improves insulin receptor and IRS-1 tyrosine phosphorylation but does not increase insulin stimulation of the association of PI 3-kinase with IRS-1; nor does it increase insulin-stimulated glucose uptake. The abnormality in association of 
PI 3-kinase with IRS-1 in insulin-resistant patients appears to be an significant defect that may result in decreased insulin-stimulated glucose disposal.

\section{Acknowledgments}

The expert technical assistance of A. Barrentine, K. Camp, J. Finlayson, G. Gomez, C. Muñoz, S. Taylor, and E. Landaker is gratefully acknowledged. P. Wolff and N. Diaz provided skilled nursing assistance. These studies were supported by grants from the National Institutes of Health (R01DK47936 to L.J. Mandarino, and R01DK24092 to R.A. DeFronzo), a VA Merit Award (R.A. DeFronzo), DK02526 (M.E. Patti), R01DK33201 (C.R. Kahn), The Markey Charitable Trust, RR-01346 (General Clinical Research Center, Audie L. Murphy Veterans Hospital), and a grant from the American Diabetes Association (L.J. Mandarino).

1. Bogardus, C., Lillioja, S., Stone, K., and Mott, D. 1984. Correlation between muscle glycogen synthase activity and in vivo insulin action in man. J. Clin. Invest. 73:1185-1190.

2. Kelley, D.E., Mokan, M., and Mandarino, L. 1992. Intracellular defects in glucose metabolism in obese patients with noninsulin-dependent diabetes mellitus. Diabetes. 41:698-706.

3. Bonadonna, R.C., et al. 1996. Roles of glucose transport and glucose phosphorylation in muscle insulin resistance of NIDDM. Diabetes. 45:915-925.

4. Pendergrass, M., et al. 1998. Insulin-induced hexokinase II expression is reduced in obesity and NIDDM. Diabetes. 47:387-394.

5. Mandarino, L.J., et al. 1987. Effect of insulin infusion on human skeletal muscle pyruvate dehydrogenase, phosphofructokinase and glycogen synthase. J. Clin. Invest. 80:655-663.

6. Cheatham, B., et al. 1994. Phosphatidylinositol 3-kinase activation is required for insulin stimulation of pp70 S6 kinase, DNA synthesis and glucose transporter translocation. Mol. Cell. Biol. 14:4902-4911.

7. Dorrestijn, J., Ouwens, D.M., Van den Berghe, N., Bos, J.L., and Maassen, J.A. 1996. Expression of a dominant-negative Ras mutant does not affect stimulation of glucose uptake and glycogen synthesis by insulin. Diabetologia. 39:558-563.

8. Kanai, F., et al. 1993. Insulin-stimulated GLUT4 translocation is relevant to the phosphorylation of IRS-1 and the activity of PI 3-kinase. Biochem. Biophys. Res. Commun. 195:762-768.

9. Lazar, D., et al. 1995. Mitogen-activated protein kinase kinase inhibition does not block the stimulation of glucose utilization by insulin.J. Biol. Chem 270:20801-20807.

10. Bak, J., Jacobsen, U., Jorgensen, F., and Pedersen, O. 1989. Insulin receptor function and glycogen synthase activity in skeletal muscle biopsies from patients with non-insulin dependent diabetes mellitus: effects of physical training. J. Clin. Endocrinol. Metab. 69:158-164.

11. Bjornholm, N., Kawano, Y., Lehtihet, M., and Zierath, J.R. 1997. Insulin receptor substrate-1 phosphorylation and phosphatidylinositol 3-kinase activity in skeletal muscle from NIDDM subjects after in vivo insulin stimulation. Diabetes. 46:524-527.

12. Hickey, M.S., et al. 1997. Insulin activation of phosphatidylinositol 3-kinase in human skeletal muscle in vivo. J. Appl. Physiol. 83:718-722.

13. Maegawa, H., Shigeta, Y., Egawa, K., and Kobayashi, M. 1991. Impaired autophosphorylation of insulin receptors from abdominal skeletal muscles in nonobese subjects with NIDDM. Diabetes. 40:815-819.

14. Nyomba, B.L., Ossowski, V.M., Bogardus, C., and Mott, D.M. 1990. Insulinsensitive tyrosine kinase: relationship with in vivo insulin action in humans. Am. J. Physiol. 258:E964-E974.

15. Hayashi, T., Wojtasweski,J.F.P., and Goodyear, L.J. 1997. Exercise regulation of glucose transport during exercise. Am.J. Physiol. 273:E1039-E1051.

16. Lund, S., et al. 1998. Evidence against protein kinase B as a mediator of contraction-induced glucose transport and GLUT4 translocation in rat skeletal muscle. FEBS Lett. 425:472-474.

17. Ren, J., et al. 1994. Exercise induces rapid increases in GLUT4 expression, glucose transport capacity, and insulin stimulated glycogen storage in muscle. J. Biol. Chem. 269:14396-14401.

18. Koval, J.A., et al. 1998. Regulation of hexokinase II activity and expression in human muscle by moderate exercise. Am. J. Physiol. 274:E304-E308.

19. O’Doherty, R., Bracy, D., Osawa, H., Wasserman, D., and Granner, D. 1994. Rat skeletal muscle hexokinase II mRNA and activity are increased by a single bout of acute exercise. Am. J. Physiol. 266:E171-E178.
20. Schneider, S.H., Amorosa, L.F., Khachadurian, A.K., and Ruderman, N.B. 1984. Studies on the mechanism of improved glucose control during regular exercise in Type 2 (non-insulin-dependent) diabetes. Diabetologia. 26:355-360.

21. Ruderman, N.B., Ganda, O.P., and Johansen, K. 1979. The effect of physical training on glucose tolerance and plasma lipids in maturity-onset diabetes. Diabetes. 28(Suppl.):89-92.

22. Mikines, K.J., Sonne, B., Farrell, P.A., Tronier, B., and Galbo, H. 1988. Effect of physical exercise on insulin sensitivity and responsiveness in humans. Am. J. Physiol. 254:E248-E259.

23. Perseghin, G., et al. 1996. Increased glucose transport-phosphorylation and muscle glycogen synthesis after exercise training in insulin resistant subjects. N. Engl. J. Med. 335:1357-1362.

24. Brozinick, J.T., and Birnbaum, M.J. 1998. Insulin, but not contraction, activates Akt/PKB in isolated rat skeletal muscle. J. Biol. Chem. 273:14679-14682.

25. Goodyear, L., Giorgino, F., Balon, T., Condorelli, G., and Smith, R. 1995. Effects of contractile activity on tyrosine phosphoproteins and PI3-kinase activity in rat skeletal muscle. Am. J. Physiol. 268:E987-E995.

26. Goodyear, L.J., et al. 1995. Insulin receptor phosphorylation, insulin receptor substrate-1 phosphorylation, and phosphatidylinositol 3-kinase activity are decreased in intact skeletal muscle strips from obese subjects. J. Clin. Invest. 95:2195-2204.

27. Koval, J., et al. 1999. Differential effects of moderate exercise and physiological hyperinsulinemia on phosphorylation and activity of insulin signaling proteins in vivo in human skeletal muscle. Med. Sci. Sports Exerc. 31:998-1004.

28. Zorzano, A., Balon, T.W. Goodman, M.N., and Ruderman, N.B. 1986. Glycogen depletion and increased insulin sensitivity and responsiveness in muscle after exercise. Am. J. Physiol. 251:E664-E669.

29. Devlin, J., Hirschman, M., Horton, E.D., and Horton, E.S. 1986. Enhanced peripheral and splanchnic insulin sensitivity in NIDDM men after a single bout of exercise. Diabetes. 36:434-439.

30. Steele, R., Wall, J., DeBodo, R., and Altszuler, N. 1956. Measurement of size and turnover rate of body glucose pool by the isotope dilution method. Am. J. Physiol. 187:15-24.

31. Lowry, O.H., Rosebrough, N.J., Fan, A.L., and Randall, R.J. 1951. Protein measurement with the Folin phenol reagent. J. Biol. Chem. 193:265-275.

32. Endemann, G., Yonezawa, K., and Roth, R. 1990. Phosphatidylinositol kinase or an associated protein is a substrate for the insulin receptor kinase. J. Biol. Chem. 265:396-400.

33. Reuter, C.W., Catling, A.D., and Weber, M.J. 1995. Immune complex kinase assays for mitogen-activated protein kinase and MEK. Methods Enzymol. 255:245-256.

34. Aronson, D., et al. 1997. Exercise stimulates the mitogen-activated protein kinase pathway in human skeletal muscle. J. Clin. Invest. 99:1251-1257.

35. Patti, M.E., et al. 1995. 4PS/IRS-2 is the alternative substrate of the insulin receptor in IRS-1 deficient mice. J. Biol. Chem. 270:24670-24673.

36. McGuire, M.C., et al. 1991. Abnormal regulation of protein tyrosine phosphatase activities in skeletal muscle of insulin resistant humans. Diabetes. 40:939-942.

37. Worm, D., et al. 1996. Altered basal and insulin-stimulated phosphotyrosine phosphatase (PTPase) activity in skeletal muscle from NIDDM patients compared with control subjects. Diabetologia. 29:1208-1214.

38. Araki, E., et al. 1994. Alternative pathway of insulin signaling in mice with targeted disruption of the IRS-1 gene. Nature. 372:186-190.

39. Rondinone, C.M., et al. 1997. Insulin receptor substrate(IRS) 1 is reduced and IRS-2 is the main docking protein for phosphatidylinositol 3-kinase in adipocytes from subjects with non-insulin-dependent diabetes mellitus. Proc. Natl. Acad. Sci. USA. 94:4171-4175.

40. Jiang, Z.Y., et al. 1999. Characterization of selective resistance to insulin signaling in the vasculature of obese Zucker $(\mathrm{fa} / \mathrm{fa})$ rats. J. Clin. Invest. 104:447-457.

41. Sasaoka, T., Draznin, B., Leitner, J.W., Langlois, W.J., and Olefsky, J.M. 1994. Shc is the predominant signaling molecule coupling insulin receptors to activation of guanine nucleotide releasing factor and p21ras-GTP formation. J. Biol. Chem. 269:10734-10738.

42. De Fea, K., and Roth, R.A. 1997. Modulation of insulin receptor substrate-1 tyrosine phosphorylation and function by mitogen-activated protein kinase. J. Biol. Chem. 272:31400-31406.

43. Dunaif, A., Xia, J., Book, C.-B., Schenker, E., and Tang, Z. 1995. Excessive insulin receptor phosphorylation in cultured fibroblasts and in skeletal muscle. J. Clin. Invest. 96:801-810.

44. Kochan, R.G., et al. 1979. Glycogen synthase activation in human skeletal muscle: effects of diet and exercise. Am. J. Physiol. 236:E660-E666.

45. Lawrence, J.C., and Roach, P.J. 1997. New insights into the role and mechanism of glycogen synthase activation by insulin. Diabetes. 46:541-547.

46. Rothman, D., Shulman, R, and Shulman, G. 1992. ${ }^{31}$ P nuclear magnetic resonance measurements of muscle glucose-6-phosphate: evidence for reduced insulin-dependent muscle glucose transport or phosphorylation in noninsulin-dependent diabetes mellitus. J. Clin. Invest. 89:1069-1075.

47. Wojtaszewski, J.F.P., Hansen, B.F., Kiens, B., and Richter, E.A. 1997. Insulin signaling in human skeletal muscle. Time course and effect of exercise. Diabetes. $\mathbf{4 6 : 1 7 7 5 - 1 7 8 1 . ~}$ 